\title{
JUDICIALIZAÇÃO DE POLÍTICAS PÚBLICAS DE SAÚDE: LEGITIMIDADE E LIMITES
}

\section{Márcio Valério Ferreira Fernandes ${ }^{1}$}

\section{RESUMO}

A judicialização da saúde é tema complexo e polêmico. Este artigo analisa o crescimento do fenômeno, levantando os principais argumentos contra e a favor da participação do Judiciário na concretização deste direito social via políticas públicas. Objetiva identificar, via pesquisa documental e bibliográfica, os requisitos para uma intervenção legítima dos tribunais. A hipótese, confirmada pelos resultados e conclusões, é a de que o Judiciário pode e deve tutelar este direito social assegurado constitucionalmente, com vistas à garantia do mínimo existencial, levando em conta a razoabilidade da pretensão e a disponibilidade financeira do Estado, especialmente quando ocorrer omissão dos outros poderes.

Palavras-chave: Direitos sociais. Saúde. Constituição. Judiciário. Políticas públicas.

\section{JUDICIALIZATION OF PUBLIC HEALTH POLICIES: LEGITIMACY AND LIMITS}

\begin{abstract}
The judicialization of health is a complex and controversial issue. This article analyzes the growth of the phenomenon, listing the main arguments against and in favor of the participation of the Judiciary in the realization of this social right through public policies. It aims to identify, through documentary and bibliographic research, the requirements for a legitimate intervention by the courts. The hypothesis, confirmed by the results and conclusions, is that the Judiciary can and must protect this constitutionally guaranteed social right, in order to secure the "existential minimum", considering the reasonableness of the petition and the financial availability of the State, especially when it occurs omission of other powers.
\end{abstract}

Keywords: Social rights. Health. Constitution. Judiciary. Public policy.

\section{INTRODUÇÃO}

O crescente aumento da judicialização na saúde, longe de ser sustentável, é preditivo de importantes dificuldades à concretização de políticas públicas nesta e em outras áreas. Um dos conceitos de sustentabilidade é o de se atender às necessidades atuais sem comprometer as possibilidades das futuras gerações de atenderem às suas próprias necessidades. Alguns

\footnotetext{
${ }^{1}$ Especialista em Gestão Pública. Mestre em Direito e Políticas Públicas pela Universidade Federal do Estado do Rio de Janeiro (UNIRIO). Rua Voluntários da Pátria, 107. Botafogo, Rio de Janeiro - RJ. CEP 22.270-000. Brasil. Endereço eletrônico: dir.marcio9@gmail.com.
} 
autores alegam que esta explosão de demandas estaria colocando em risco a continuidade de outros programas sociais. Por outro lado, surge a argumentação de que a saúde é direito do cidadão e dever do Estado.

Praticamente todos os cidadãos, em algum momento de suas vidas, precisarão da assistência médica, a qual tem o potencial de afetar um importante tema para o Direito e que está relacionado a um dos fundamentos da República: a dignidade da pessoa humana. Acredita-se, que a análise da problemática envolvendo o conflito entre os recursos limitados do orçamento e as necessidades ilimitadas da população poderá gerar propostas para os que tomam decisões orçamentárias e para os formuladores de políticas em saúde. Ocorre que tal efetividade de direitos precisa ter parâmetros.

Nesta órbita, evidencia-se como necessária uma forma de aperfeiçoar e organizar a atuação do Judiciário, racionalizando a judicialização, notadamente com a parceria de núcleos de apoio técnico especializados na área médica e uma argumentação paralela: a de que o ideal seria uma solução coletiva (macrojustiça), atenuando as demandas por soluções individuais (microjustiça).

No artigo apresenta-se o conceito de judicialização em saúde e o advento dos Núcleos de Apoio Técnico do Poder Judiciário (NAT-Jus), em 2016, com a finalidade de fornecer subsídios aos magistrados nas sentenças judiciais que pleiteiam o acesso a medicamentos. Tais núcleos surgiram para racionalizar conflitos e possibilitar decisões mais céleres, produzindo decisões baseadas em evidências científicas. Aborda-se a questão da legitimidade do Judiciário como participante na formulação de políticas públicas, especialmente quando ocorre inércia dos Poderes Legislativo e Executivo.

O tema, portanto, analisa a legitimidade do poder Judiciário como garantidor das políticas públicas na área da saúde, com vistas à concretização de direitos sociais constitucionalizados, levando-se em conta o basilar princípio da separação dos poderes (harmônicos entre si e complementares nos interesses da Federação).

O Estado brasileiro tem deveres em relação à sociedade, garantias constitucionais de determinados direitos que precisam ser concretizados, inclusive para justificar os diversos tipos de tributos arrecadados, notadamente os vinculados. Quando ocorre uma lacuna em políticas públicas (seja por inexistência, insuficiência ou ineficácia), um novo risco à 
sustentabilidade social passa a existir e o desrespeito aos direitos humanos se evidencia, prejudicando o desenvolvimento.

Levando em conta os princípios constitucionais e a consciência de que as políticas públicas sempre envolvem escolhas (pois não estão disponíveis recursos para tudo), identifica-se a seguinte pergunta-problema: Quais são os requisitos para uma intervenção legítima do Judiciário ao assegurar a concretização destes direitos previstos na Constituição da República Federativa do Brasil (CRFB/1988, art. 6º)?

A hipótese atribui ao poder Executivo uma eventual omissão ao não concretizar estas prestações constitucionais; em alguns casos por sua inércia e, em outros, por lacunas deixadas pelo poder Legislativo, a quem compete a promulgação de legislação complementar que regulamente a provisão pelos diferentes entes da Federação e o exercício destes direitos. Neste contexto, o poder Judiciário em "harmonia compensatória" com os demais poderes (levando em conta o sistema de freios e contrapesos e os interesses da República), pode e deve interferir provendo estes direitos sociais, com vistas à garantia do mínimo existencial, levando em conta a razoabilidade da pretensão e a disponibilidade financeira do Estado.

Tal atuação nem sempre é protagonizada aliando os aspectos socioambientais (não apenas ambientais, mas também, sociais) aos econômicos, integrando-os aos produtos e serviços ofertados ao cidadão-cliente, assegurando uma atuação economicamente viável, socialmente justa, ambientalmente correta e culturalmente aceita, de forma a garantir o fortalecimento e a harmonia da sociedade, das instituições e mesmo do Estado.

Para nortear o entendimento deste problema, elege-se o seguinte objetivo geral: definir os requisitos para intervenção do Judiciário em políticas públicas, de acordo com o STF. Para o alcance do objetivo geral, detalham-se os objetivos específicos abaixo indicados:

- Analisar os argumentos contra o controle de políticas públicas pelo Judiciário;

- Examinar os argumentos a favor do controle de políticas públicas pelo Judiciário.

Quando a não prestação de direitos sociais previstos na Constituição colocam em risco a integridade física, a manutenção da saúde ou a sobrevivência dos cidadãos, evidenciase uma grave omissão que precisa ser remediada pelo Direito. 
Os alarmantes riscos sociais e econômicos que decorrem do problema foi mais uma vez colocado em evidência por ocasião da Audiência Pública ${ }^{2}$ convocada pela presidente do Conselho Nacional de Justiça (CNJ) e do Supremo Tribunal Federal (STF), ministra Cármen Lúcia, realizada em 11 de dezembro de 2017, com a presença de representantes do Executivo, do Judiciário, de profissionais e usuários do SUS, dentre outros grupos de interesse.

De acordo com a agência de notícias do CNJ, "entre 2008 e 2015, o gasto do Estado brasileiro para prestar serviços ligados à área da saúde em cumprimento a decisões judiciais cresceu $1.300 \%$, segundo o Ministério da Saúde - de R \$ 70 milhões para R \$ 1 bilhão só em medicamentos".

É tema de interesse público, que afeta todos os entes da Federação, já que "entre 2010 e 2016, o aumento dos gastos com ações judiciais foi de 1.010\%. Em 2017, os gastos dos estados e municípios somaram R\$ 7 bilhões"; os da União se aproximaram dos R\$ 1 bilhão ${ }^{3}$, conforme informações da Fundação Oswaldo Cruz (Fiocruz).

Os métodos selecionados para este trabalho são a pesquisa documental através de fontes oficiais, documentos jurídicos e arquivos estatísticos na internet (Ministério da Saúde, IBGE, Fiocruz, Ministério do Planejamento, Resoluções do CNJ, audiências públicas e decisões do STF, dentre outras) e a pesquisa bibliográfica (livros, reportagens, artigos e teses).

Objetiva-se a análise da temática em busca de propostas e possiblidades para a solução do problema. Portanto, quanto à natureza, pretende-se uma pesquisa aplicada: capaz de gerar aplicação na realidade fática da sociedade. Com relação ao tipo de abordagem do problema, uma pesquisa qualitativa (com objetivo exploratório, com amostras reduzidas, fundamentada em autores de formação jurídica e em pronunciamentos de autoridades dos três poderes).

Pretende-se analisar o acesso às políticas públicas em saúde, previstas no Direito brasileiro e na Constituição de 1988, sem perder de vista a sustentabilidade social e econômica, de modo que as gerações futuras possam contar com um sistema público de saúde ainda melhor.

\footnotetext{
${ }^{2}$ Notícia disponível no sítio do CNJ: < http://www.cnj.jus.br/noticias/cnj/85913-audiencia-expoe-complexidadeem-debate-plural-sobre-judicializacao-da-saude>. Acesso em 10 out. 2018.

${ }^{3}$ Reportagem disponível em <https://www.fiocruzbrasilia.fiocruz.br/sa\%C3\%BAde-nos-munic\%C3\%ADpiosbrasileiros-um-retrato-nacional>. Consulta em 21 fev. 2018
} 


\section{O QUE SIGNIFICA JUDICIALIZAÇÃO DA SAÚDE?}

"A dor tem pressa"

Ministra Cármen Lúcia, Presidente do Conselho Nacional de Justiça (CNJ) e do Supremo Tribunal federal (STF)

O que vem ocorrendo de forma gradativa é que o Estado oferece uma política universalista, mas que nem sempre funciona. Então, o cidadão (ou sua família) recorre à jurisdição e consegue uma internação, uma vaga em UTI, a liberação de procedimentos ou medicamentos de alto custo. Levando em conta que recursos limitados estão disponíveis para atender a uma demanda crescente, o Judiciário pode estar afetando (ou mesmo prejudicando) o planejamento da política pública, para concretizar atendimentos individuais.

\subsection{O que é judicialização?}

A judicialização das políticas públicas na área da saúde é um tema complexo e polêmico, que pode ser abordado a partir de uma série de pontos de vista: sob a ótica do Judiciário, do Executivo, do Legislativo, do cidadão-cliente, dos cientistas políticos, dos diversos operadores do Direito. O texto apresenta argumentos contrários e argumentos favoráveis à solução, pelo Judiciário, das controvérsias que emergem das prestações insuficientes ou inexistentes devidas pelo Estado aos cidadãos, mediante previsão constitucional.

Nas palavras de Barroso:

Judicialização significa que algumas questões de larga repercussão política ou social estão sendo decididas por órgãos do Poder Judiciário, e não pelas instâncias políticas tradicionais: o Congresso Nacional e o Poder Executivo - em cujo âmbito se encontram o Presidente da República, seus ministérios e a administração pública em geral. [...] a judicialização envolve uma transferência de poder para juízes e tribunais, com alterações significativas na linguagem, na argumentação e no modo de participação da sociedade. $O$ fenômeno tem causas múltiplas. Algumas delas expressam uma tendência mundial; outras estão diretamente relacionadas ao modelo institucional brasileiro. (BARROSO, 2012, p. 24) 
Para a Consultoria Jurídica da Advocacia Geral da União junto ao Ministério da Saúde - CONJUR/MS, judicialização significa "uma forma de acesso às ações e serviços públicos de saúde. Esta garantia constitucional, quando utilizada de forma indevida, gera efeitos negativos, com impactos orçamentários e financeiros capazes de afetar a execução das políticas públicas de saúde, destacando-se as ações judiciais na área de assistência farmacêutica e oncológica". (AGU et al., 2017, p. 2)

Para Secchi (2016) problema público é algum excesso ou carência que existe na sociedade. O autor compara o problema público com uma doença, fazendo analogia com a área médica. Assim, a política pública seria o tratamento dessa doença, uma tentativa de intervenção para a solução de um problema público, uma diretriz voltada para a solução de um problema público

Seja de uma perspectiva coletiva, que costuma ser mais facilmente percebida, geralmente provocada pelo Ministério Público ou de um ponto de vista individual, que dificulta o exame e o debate, uma série de fatores orçamentários e o questionamento da legitimidade dos atores envolvidos, interferem na análise das políticas públicas com maior ou menor influência, dependendo do discurso adotado e dos interesses em questão.

O entendimento do STF, a respeito dos limites e possibilidades de o Poder Judiciário interferir em políticas públicas formuladas e implementadas pelo Legislativo e Executivo, pode ser resumida na seguinte ementa:

AMPLIAÇÃO E MELHORIA NO ATENDIMENTO DE GESTANTES EM MATERNIDADES ESTADUAIS - DEVER ESTATAL DE ASSISTÊNCIA MATERNO-INFANTIL RESULTANTE DE NORMA CONSTITUCIONAL. OBRIGAÇÃO JURÍDICO-CONSTITUCIONAL QUE SE IMPÕE AO PODER PÚBLICO, INCLUSIVE AOS ESTADOSMEMBROS. CONFIGURAÇÃO, NO CASO, DE TÍPICA HIPÓTESE DE OMISSÃO INCONSTITUCIONAL IMPUTÁVEL AO ESTADOMEMBRO. DESRESPEITO À CONSTITUIÇÃO PROVOCADO POR INÉRCIA ESTATAL (RTJ 183/818-819) COMPORTAMENTO QUE TRANSGRIDE A AUTORIDADE DA LEI FUNDAMENTAL DA REPÚBLICA (RTJ 185/794-796) [...] NECESSIDADE DE OBSERVÂNCIA DE CERTOS PARÂMETROS CONSTITUCIONAIS (PROIBIÇÃO DE RETROCESSO SOCIAL, PROTEÇÃO AO MÍNIMO EXISTENCIAL, VEDAÇÃO DA PROTEÇÃO INSUFICIENTE E PROIBIÇÃO DE EXCESSO). DOUTRINA PRECEDENTES DO 
SUPREMO TRIBUNAL FEDERAL EM TEMA DE IMPLEMENTAÇÃO DE POLÍTICAS PÚBLICAS DELINEADAS NA CONSTITUIÇÃO DA REPÚBLICA (RTJ 174/687 RTJ 175/1212-1213 RTJ 199/1219-1220) [...] DOUTRINA PRECEDENTES RECURSO DE AGRAVO IMPROVIDO. (RE 581.352-AgR, Segunda Turma, Rel. Min. CELSO DE MELLO, DJe de 22/11/2013). Disponível em < http://www.stf.jus.br/portal/jurisprudencia/visualizarEmenta.asp?s1=000241 042\&base=baseMonocraticas $>$. Acesso em 26 jan. 2019.

A decisão considerou a reserva do possível inaplicável, caso tal invocação possa comprometer o núcleo básico que caracteriza o chamado mínimo existencial: "Tal avaliação seria dever do Poder Judiciário na implementação de políticas públicas instituídas pela Constituição e não concretizadas pelo poder público." Nesse sentido, prosseguem na defesa com expressões como "atividade de fiscalização judicial" de políticas sociais, justificáveis "pela necessidade de observância de certos parâmetros constitucionais como, por exemplo, proibição de retrocesso social, proteção ao mínimo existencial, vedação da proteção insuficiente e proibição de excesso". (MORAIS e BRUM, 2016, p. 89-91)

Quando a questão é o controle de políticas públicas, as decisões do STF têm seguido um padrão de discurso, com a seguinte argumentação: “A jurisprudência desta Corte entende ser possível ao Poder Judiciário determinar ao Estado a implementação, em situações excepcionais, de políticas públicas previstas na constituição sem que isso acarrete contrariedade ao princípio da separação dos poderes.” (MORAIS e BRUM, 2016, p. 92)

Uma decisão do ministro Celso de $\mathrm{Mello}^{4}$ (ADPF 45) influenciou vário outros precedentes com conteúdo perfeccionista em relação à judicialização de políticas públicas, por vezes citando aquela Arguição de Descumprimento de Preceito Fundamental:

É certo que não se inclui, ordinariamente, no âmbito das funções institucionais do Poder Judiciário - e nas desta Suprema Corte, em especial a atribuição de formular e de implementar políticas públicas (JOSÉ

\footnotetext{
${ }^{4}$ Sua respeitável posição é a defesa da força jurídica vinculante das Constituições e a consequente aplicação das normas constitucionais na imediata geração de direitos para os administrados e o consequente dever prestacional imposto ao Estado. Assim, legitima-se a atuação do Judiciário, como freio e contrapeso aos poderes Executivo e Legislativo, bem como a seus desvios, dando importância às motivações dos atos administrativos, aspecto fundamental na defesa do particular perante específicas ações e omissões da Administração. Esta dissertação apresenta um contraponto, um adendo, no capítulo que trata de orçamento e reserva do possível.
} 
CARLOS VIEIRA DE ANDRADE, "Os Direitos Fundamentais na Constituição Portuguesa de 1976”, p. 207, item n.05, Almedina, Coimbra), pois, nesse domínio, o encargo reside, primariamente, nos Poderes Legislativo e Executivo. Tal incumbência, no entanto, embora em bases excepcionais, poderá atribuir-se ao Poder Judiciário, se e quando os órgãos estatais competentes, por descumprirem os encargos político-jurídicos que sobre eles incidem, vierem a comprometer, com tal comportamento, a eficácia e a integridade de direitos individuais e/ou coletivos impregnados de estatura constitucional, ainda que derivados de clausulas revestidas de conteúdo programático." (Disponível em <http://www.stf.jus.br $>$. Apud MORAIS e BRUM, 2016, p. 93-94)

Note-se, contudo, que o Ministro Gilmar Mendes, presidente do Conselho Nacional de Justiça à época, ao resolver publicar a Recomendação CNJ no 31 (de 30/03/2010), indicando aos Tribunais a "adoção de medidas visando a melhor subsidiar os magistrados e demais operadores do direito, para assegurar maior eficiência na solução das demandas judiciais envolvendo a assistência à saúde”. O documento evidencia o respeito ao princípio da separação dos poderes ao reconhecer a primazia da Administração na elaboração de políticas públicas, notadamente, ao considerar "reiteradas reivindicações dos gestores para que sejam ouvidos antes da concessão de provimentos judiciais de urgência $^{5}$ e a necessidade de prestigiar sua capacidade gerencial, as políticas públicas existentes e a organização do sistema público de saúde".

$\mathrm{Na}$ mesma exortação jurídica, o Presidente do CNJ, recomenda aos Tribunais de Justiça dos Estados e aos Tribunais Regionais Federais que "orientem através das suas corregedorias, aos magistrados vinculados, que ouçam, quando possível, preferencialmente por meio eletrônico, os gestores, antes da apreciação de medidas de urgência" (Resolução n³1 CNJ, 2010, inciso II alínea “b”).

A professora Ada Pellegrini, ao apresentar o fundamento constitucional do controle de políticas públicas pelo poder judiciário, lembra que no período da primeira geração de direitos fundamentais, ao Estado bastava abster-se, para que o cidadão pudesse exercer sua liberdade. A preocupação constitucional era apenas proteger o cidadão da ingerência estatal. Após a Revolução Industrial, a este dever acrescentou-se um dever de dar, fazer ou prestar,

\footnotetext{
${ }^{5}$ Um fator que precisa ser levado em conta é a urgente necessidade que alguns pacientes ou seus familiares apresentam em tais situações, inviabilizando, em alguns casos, as resoluções extrajudiciais e confirmando a importância de um Judiciário eficiente e bem assessorado.
} 
"uma atuação positiva, que realmente permita a fruição dos direitos de liberdade da primeira geração, assim como dos novos direitos". (GRINOVER in SALIBA et al., 2010, p. 1-2)

\subsection{Argumentos contra o controle de políticas públicas pelo Judiciário}

Ao examinarmos as decisões do STF, verificamos que existe uma discordância de opiniões: alguns defendem a lógica de intervenção do Poder Judiciário nas políticas públicas, com o pré-requisito de se atender aos direitos fundamentais, o mínimo existencial, a dignidade humana; outros adotam uma posição de não intervenção, entendendo violadoras do princípio da separação de poderes as ordens judiciais que disponham sobre a inadequação de políticas públicas, pois “a forma como o Estado-Membro vai garantir o direito à segurança pública (por exemplo) há de ser definida no quadro de políticas sociais e econômicas cuja formulação é atribuição exclusiva do Poder Executivo". (MORAIS e BRUM, 2010, p. 103)

Conforme assevera Barroso (2007) no âmbito de ações coletivas e/ou de ações abstratas de controle de constitucionalidade, será possível discutir a inclusão de novos medicamentos nas políticas de assistência. Tal inclusão, contudo, deve ser excepcional, uma vez que as complexas avaliações técnicas competem primariamente aos Poderes Legislativo e Executivo. Ressalte-se que a judicialização abusiva pode causar a não concretização da Constituição de 1988, como decorrência recorrente microjustiça, desfalcando a coletividade, como na alegoria do "cobertor curto" que não consegue cobrir a todos.

Nos últimos anos, o STF passou a dar maior atenção a este tópico em políticas públicas que trata da outorga de medicamentos e mandados de tratamentos pela via judicial, culminando no reconhecimento, em agosto de 2018, da legitimidade do Ministério Público (Recurso Extraordinário 605533, com repercussão geral) para ajuizar ação civil pública para o fornecimento de medicamentos a portadores de doenças específicas (incluindo hipotireoidismo, cujo tratamento tem custo elevado).

Barroso (2012) traz à baila dois pontos que a doutrina constitucional contemporânea vem explorando há tempos e que têm sua importância quando se fala em avaliar qual (ou quais) dos três poderes da República estariam mais aptos a tomar decisões mais técnicas: a que trata das "capacidades institucionais" e a que sopesa os chamados "efeitos sistêmicos": 
Capacidade institucional envolve a determinação de qual Poder está mais habilitado a produzir a melhor decisão em determinada matéria. Temas envolvendo aspectos técnicos ou científicos de grande complexidade podem não ter no juiz de direito o árbitro mais qualificado, por falta de informação ou conhecimento específico. Formalmente, os membros do Poder Judiciário sempre conservarão a sua competência para o pronunciamento definitivo. Mas em situações como as descritas, normalmente deverão eles prestigiar as manifestações do Legislativo ou do Executivo, cedendo o passo para juízos discricionários dotados de razoabilidade. Em questões como demarcação de terras indígenas ou transposição de rios, em que tenha havido estudos técnicos e científicos adequados, a questão da capacidade institucional deve ser sopesada de maneira criteriosa. (BARROSO, 2012, p. 30)

Ocorre que o argumento da incapacidade técnica do Judiciário perdeu força a partir da criação dos Núcleos de Avaliação de Tecnologia em Saúde (NATS) e dos Núcleos de Apoio Técnico do Poder Judiciário (NAT-Jus) ${ }^{6}$, em 2016, um convênio entre o Hospital SírioLibanês (referência em São Paulo), o Conselho Nacional de Justiça, Sistema Único de Saúde (SUS), o Ministério da Saúde e Governo Federal, colocando à disposição da Justiça uma base de dados com pareceres médicos para ajudarem na avaliação de juízes nas questões de saúde, com a finalidade de fornecer subsídios aos magistrados nas sentenças judiciais que pleiteiam o acesso a medicamentos, aumentando as possibilidades de uma prestação jurisdicional mais racional. $^{7}$

A consciência de que a saúde é um direito do cidadão e um dever do Estado tem levado milhares de pessoas a recorrerem à Justiça quando necessitam de um medicamento ou procedimento que não conseguem adquirir no Sistema Único de Saúde (SUS). Segundo a Secretaria de Estado de Saúde e Defesa Civil do Rio de Janeiro (Sesdec-RJ), cerca de mil novos mandados são expedidos mensalmente com pedidos de medicamentos. (Disponível em $<$ https://portal.fiocruz.br/noticia/judicializacao-da-saude-e-tema-de-estudosna-fiocruz>. Consulta em 22 fev. 2018).

Visto que um dos mais fortes argumentos contra o mover da jurisdição em prol de necessidades individuais, que seria a falta de conhecimento científico para decisões mais

\footnotetext{
${ }^{6}$ Comitês criados com a finalidade de fornecer subsídios científicos, através de notas técnicas e pareceres técnicos científicos (elaborados a partir da medicina baseada em evidências) para suporte ao Judiciário nas decisões relacionadas à temática da saúde. Compostos por membros de vários órgãos como o Ministério da Saúde (MS), Agência Nacional de Vigilância Sanitária (ANVISA), Conselho Nacional de Justiça (CNJ), Hospital Sírio-Libanês (HSL) e professores da faculdade de medicina da USP.

${ }^{7}$ Notícia disponível em <http://www.cnj.jus.br/noticias/cnj/83799-a-dor-tem-pressa-diz-presidente-do-cnj-aoabrir-oficina-sobre-saude〉. Acesso em 25 fev. 2018.
} 
seguras, em instâncias superiores, o Hospital Sírio-Libanês passou a responder pela capacitação de juízes, oferecendo uma plataforma com informações técnicas e evidências científicas.

De acordo com o site do $\mathrm{CNJ}^{8}$, os magistrados e tribunais passaram a "contar com a consultoria de especialistas da área para auxiliá-los em relação às informações técnicas”, minimizando os conflitos entre as demandar individuais e as coletivas, possibilitando condições para decidir com mais celeridade e com subsídios da informação e da experiência de médicos, produzindo decisões com melhor fundamentação.

Barroso (2007) adverte sobre a necessidade de gestão de recursos limitados:

Preocupado com a solução dos casos concretos - o que se poderia denominar de microjustiça -, o juiz fatalmente ignora outras necessidades relevantes e a imposição inexorável de gerenciar recursos limitados para o atendimento de demandas ilimitadas: a macrojustiça. Ora, na esfera coletiva ou abstrata examina-se a alocação de recursos ou a definição de prioridades em caráter geral, de modo que a discussão será prévia ao eventual embate pontual entre micro e macrojustiças. [...] a decisão eventualmente tomada no âmbito de uma ação coletiva ou de controle abstrato de constitucionalidade produzirá efeitos erga omnes, nos termos definidos pela legislação, preservando a igualdade e universalidade no atendimento da população. Ademais, nessa hipótese, a atuação do Judiciário não tende a provocar o desperdício de recursos públicos, nem a desorganizar a atuação administrativa, mas a permitir o planejamento da atuação estatal. Com efeito, uma decisão judicial única de caráter geral permite que o Poder Público estruture seus serviços de forma mais organizada e eficiente. (BARROSO, 2007, p. 32-33)

Os NAT-Jus, neste contexto, apesar de não fazerem com que as demandas judiciais reduzam imediatamente, contribuem para a redução de decisões inadequadas ao oferecerem suporte aos magistrados. Voltando aos argumentos contrários, Gouvêa (2003) prossegue inclusive defendendo o princípio da separação dos poderes em seu livro sobre as omissões administrativas:

O princípio da separação de poderes compreende, portanto, uma vertente políticofuncionalista que não se pode desprezar, sob pena de restringir-se a soberania popular. Afora esta componente, a separação de poderes traduz-se

\footnotetext{
${ }^{8}$ Notícia disponível em <http://www.cnj.jus.br/noticias/cnj/84538-laudo-para-ajudar-juizes-em-causas-de-saudecomeca-a-ser-utilizado-em-maio>. Acesso em 26 mar. 2018.
} 
numa consideração técnico-operacional. O Legislativo e principalmente o Executivo acham-se aparelhados de órgãos técnicos capazes de assessorá-los na solução de problemas mais complexos, em especial daqueles campos que geram implicações macropolíticas, afetando diversos campos de atuação do poder público. O Poder judiciário, por sua vez, não dispõe de iguais subsídios; a análise que faz do caso concreto tende a perder de vista possíveis implicações fáticas e políticas da sentença, razão pela qual os problemas de maior complexidade - incluindo a implementação de direitos prestacionais - devem ser reservados ao administrador público. (GOUVÊA, 2003, p. 22-23)

Tal posição percebe a judicialização das políticas públicas como uma violação ao princípio da separação de poderes, alegando lesão à ordem e à economia pública. A legalidade orçamentária, com uma previsão maior de valores para situações emergenciais ou determinadas pelo judiciário, talvez possa harmonizar demandas sociais e as relações entre os três poderes. Uma reflexão sobre a possibilidade de uma gestão mais previdente da alocação de recursos, em conformidade com os artigos 198 (parágrafo segundo) e 212 da Constituição Federal.

Para os que são contrários à reivindicação judicial individual destes direitos, os tribunais, ao tratar de cada caso concreto, precisam levar em conta as demandas previstas pelo orçamento público e pelo planejamento governamental os quais, ao menos em um esforço teórico, levam em conta as prioridades de curto e médio prazo com um escopo mais voltado para a coletividade. Existe um risco de prejuízo social e financeiro, caso as decisões com beneficiários individuais se multipliquem indefinidamente.

"A adoção de uma forma de Estado que deve garantir a realização/promoção de direitos, nomeados sociais, altera a função do Poder Judiciário. Afirma o Supremo Tribunal Federal que não cabe a ele definir políticas públicas e determinar prioridades, visto que isso já foi estabelecido pela Constituição. Cabe ao Judiciário apenas verificar se o exercício discricionário do poder de legislar e de administrar conduz à concretização dos resultados objetivados na Constituição". (RIBAS, 2014, p. 56)

De acordo com Ferreira Filho (1996, p. 51), “a garantia que o Estado dá a esses direitos (sociais) é a instituição de serviços públicos a eles correspondentes. Trata-se de uma garantia institucional, portanto". 
Morais e Brum (2016) apresentam uma crítica sobre um possível perfeccionismo interpretativo, um concebível lapso na análise da realidade quando da análise da ADPF 45, que inaugurou o entendimento do STF sobre o controle judicial de políticas públicas. Os autores alegam que, na ocasião, o ministro Celso de Mello falou em passagem, de modo opinativo (não formulando enunciado), sobre direitos fundamentais, reserva do possível, mínimo existencial, mas o fez de forma vaga (MORAIS e BRUM, 2016, p. 97).

Bercovici (2004) condenava a interferência, alegando que os juízes acabariam por assumir um status de criadores de direitos (em vez de garantidores), favorecendo o que passou a ser conhecido como constituição infinita, "subtraindo as políticas públicas das maiorias parlamentares, eleitas e responsáveis, e transferindo-as para a 'tecnocracia das jurisdições"”, referindo-se ao judiciário. (MORAIS e BRUM, 2016, p. 99)

\subsection{Argumentos a favor do controle de políticas públicas pelo Judiciário}

Um dos argumentos visa trazer a ideia de que a decisão do juiz segue as normas constitucionais que fixaram a competência comum dos Entes da Federação, para cuidar da saúde e assistência pública (art. 23, II, CRFB). De acordo com RIBAS e SOUZA FILHO (2014) "Como toda atividade política exercida pelo Legislativo e pelo Executivo deve se compatibilizar com a Constituição, cabe ao Poder Judiciário analisar sua atuação/omissão sob o prisma do atendimento aos fins do Estado, ou seja, em última análise a sua constitucionalidade."

Assim, a alegação de violação ao princípio da separação dos Poderes não justificaria a inércia do Poder Executivo em cumprir suas prestações constitucionais, como a garantia do direito à saúde de todos, previsto no artigo 196 da Constituição. Direitos fundamentais sociais, como o direito à saúde, devem ter eficácia imediata e integral segundo esta linha de raciocínio.

A Constituição Federal de 1988, lei maior do nosso ordenamento jurídico, nos permite entender que é possível a existência de tutelas especiais para certos direitos sociais, especialmente quando da ocorrência de flagrante omissão dos poderes legislativo e executivo: "Essas intervenções do Judiciário não ferem o princípio da separação dos poderes, uma vez que tal princípio foi remodelado pelo novo constitucionalismo, na medida em que este deixou de ser forma e se converteu em substância” (RIBAS, 2014). 
Para não dar uma ênfase desmedida à questão da separação dos poderes, que tem sua importância, convém a lembrança de que os poderes precisam ser harmônicos entre si com a finalidade de concretizarem a os objetivos da República Federativa. Pelas irrepreensíveis lições de Canela Junior", se por um lado o Judiciário tem a incumbência de "investigar o fundamento de todos os atos estatais a partir dos objetivos fundamentais inseridos na Constituição" (art. $3^{\circ}$ da CRFB, verificando sua constitucionalidade), por outro lado, o conceito de política estatal inclui o mesmo Judiciário no núcleo de sua formulação. Seguindose esta linha argumentativa, pode-se assim conceituar a política estatal:

\begin{abstract}
"Por política estatal - ou políticas públicas - entende-se o conjunto de atividades do Estado tendentes a seus fins, de acordo com metas a serem atingidas. Trata-se de um conjunto de normas (Poder Legislativo), atos (Poder Executivo) e decisões (Poder Judiciário) que visam à realização dos fins primordiais do Estado. [...] Diante dessa nova ordem, denominada de judicialização da política", (muito diferente, acrescente-se, da politização do Judiciário) "contando com o juiz como coautor das políticas públicas, fica claro que sempre que os demais poderes comprometerem a integridade e a eficácia dos fins do Estado - incluindo as dos direitos fundamentais, individuais ou coletivos - o Poder Judiciário deve atuar na sua função de controle." (SALIBA et al., 2010, p. 4, grifo nosso)
\end{abstract}

O posicionamento emblemático, lembrado em tantos outros semelhantes, a favor da intervenção do Poder Judiciário no controle de políticas públicas vem do STF, na ADPF 45-9, que passou a servir de base para muitas outras, em decisão monocrática do Ministro Celso de Mello, que assim se pronunciou:

"É certo que não se inclui, ordinariamente, no âmbito das funções institucionais do Poder Judiciário e nas desta Suprema Corte, em especial - a atribuição de formular e de implementar políticas públicas (JOSÉ CARLOS VIEIRA DE ANDRADE, "Os Direitos Fundamentais na Constituição Portuguesa de 1976", p. 207, item n.05, 1987, Almedina, Coimbra), pois, nesse domínio, o encargo reside, primariamente, nos Poderes Legislativo e Executivo. Tal incumbência, no entanto, embora em bases excepcionais, poderá atribuir-se ao Poder Judiciário, se e quando os órgãos estatais competentes, por descumprirem os encargos político-jurídicos que sobre eles

\footnotetext{
${ }^{9}$ Esta pesquisa adota, com destaque, o conceito de sua autoria que define políticas públicas como "o conjunto de normas (Poder Legislativo), atos (Poder Executivo) e decisões (Poder Judiciário) que visam à realização dos fins primordiais do Estado". Sua teoria sustenta que, no controle de políticas públicas pelo Judiciário, devem ser avaliadas a possibilidade de fruição do direito social assegurado constitucionalmente e a eventual desigualdade social gerada pela ausência desta satisfação adequada. (CANELA JUNIOR, 2011, p. 156)
} 
incidem, vierem a comprometer, com tal comportamento, a eficácia e a integridade de direitos individuais e/ou coletivos impregnados de estatura constitucional, ainda que derivados de cláusulas revestidas de conteúdo programático. Cabe assinalar, presente esse contexto - consoante já proclamou esta Suprema Corte - que o caráter programático das regras inscritas no texto da Carta Política "não pode converter-se em promessa constitucional inconsequente, sob pena de o Poder Público, fraudando justas expectativas nele depositadas pela coletividade, substituir, de maneira ilegítima, o cumprimento de seu impostergável dever, por um gesto irresponsável de infidelidade governamental ao que determina a própria Lei do Estado" (RJ 175/1212-1213, Rel. Min. CELSO DE MELLO)". (ibidem, p. 5-6, grifo nosso)

A laureada Professora titular da USP, Ada Pellegrini Grinover ${ }^{10}$, que considerava a judicialização como "a insatisfação do povo com o que não obtém administrativamente" resume bem a questão, ao apontar que a posição do STF é pela necessidade de certos requisitos para uma intervenção ética do Judiciário no controle de políticas públicas: o limite fixado pelo mínimo existencial a ser garantido ao cidadão; a razoabilidade da pretensão individual/social deduzida em face do Poder Público e a existência de disponibilidade financeira do Estado para tornar efetivas as prestações positivas dele reclamadas. (SALIBA et al., 2010, p. 6)

\section{EXEMPLOS NO CASO DA SAÚDE}

O STF também já se pronunciou reafirmando o direito à assistência à saúde, cujo encargo constitucional é do Estado, ressaltando que "a Administração Pública se submete ao império da lei, até mesmo no que toca à conveniência e oportunidade do ato administrativo". (SALIBA et al, 2010, p. 5)

Uma política pública nesta área deve viabilizar o atendimento do maior número de cidadãos sem causar uma sobrecarga no orçamento. Parecem não atender ao requisito da razoabilidade, alguns julgados em liminares individuais que concedem ao demandante medicamentos caríssimos ou não aprovados pelas agências reguladoras brasileiras.

\footnotetext{
${ }^{10} \mathrm{O}$ referencial teórico apropriado no presente texto inclui a defesa de uma atuação ativa do Judiciário, especialmente nas omissões do Legislativo e do Executivo, pensamento importado do trabalho de Ada Pellegrini (1933-2017). Sua teoria sobre o Estado de Direito incluiu a intervenção do juiz nas políticas públicas quando a Administração "não faz o que deveria fazer".
} 
Neste caso, também as lições do Professor Paulo Mendonça (informação verbal) ${ }^{11}$ advertem não se tratar de uma política pública que não exista ou que tenha sido mal elaborada, mas tratar-se de caso personalíssimo, raro, que não deveria onerar o erário, deixando sem cobertura casos mais abrangentes e previstos pela regulação, com a inobservância das listas de medicamentos já homologados para esse tipo de assistência (Relação Nacional de Medicamentos Essenciais - Rename ${ }^{12}$ ). Sua dicção aponta para a necessidade de homologação pelos órgãos competentes e para a observância da reserva do possível.

Ou seja, uma vez que Estado se propôs a fornecer certo medicamento, por meio de política pública de saúde à qual foi dada publicidade, via Sistema Único de Saúde (SUS), caso o administrado solicite administrativamente e lhe seja negado, torna-se perfeitamente viável a demanda para que o Poder Judiciário exija da Administração o cumprimento de uma prestação revestida de legalidade, publicidade, moralidade e legitimidade.

\subsection{Requisitos para intervenção do Judiciário, de acordo com o STF}

\subsubsection{O mínimo existencial}

É o núcleo central que, uma vez descumprido, justificaria a intervenção do Judiciário nas políticas públicas, para criá-las, corrigir seus rumos ou implementá-las (SALIBA et al., 2010, p. 7). A estrita observância dos limites à intervenção judicial, assim como o exato conceito de políticas públicas (como programas e ações tendentes ao atingimento dos objetivos do Estado brasileiro), serão suficientes para conter os abusos (SALIBA et al, 2010, p. 12). Para Barcellos (2012, p. 248) "o mínimo existencial é formado pelas condições básicas para a existência e corresponde à parte do princípio da dignidade da pessoa humana à qual se deve reconhecer eficácia jurídica e simétrica, podendo ser exigida judicialmente em caso de inobservância".

Nos casos em que o fármaco não esteja presente na lista, para que sua inclusão possa ocorrer, Barroso (2007) sustenta que

\footnotetext{
${ }^{11}$ Aula do Mestrado em Direito, na Universidade Federal do Estado do Rio de Janeiro, proferida em 30/11/2017.

${ }^{12}$ Esta Relação é constantemente revisada e atualizada pela Comissão Técnica e Multidisciplinar de Atualização da Rename (Comare), instituída pela Portaria GM no. 1.254/2005, e composta por órgãos do governo, incluindo instâncias gestoras do SUS, universidades, entidades de representação de profissionais da saúde. O CFF é uma das entidades-membro desta Comissão, sendo representado por técnicos do Cebrim/CFF, o qual participa ativamente do processo de revisão da Rename desde 2001. Informação disponível no sítio do Conselho Federal de Farmácia, em < http://www.cff.org.br/pagina.php?id=140>. Acesso em 17 jan. 2019.
} 
o Judiciário só deve determinar que a Administração forneça medicamentos de eficácia comprovada, excluindo-se os experimentais e os alternativos. Ademais, o Judiciário deve, como regra, optar por substâncias disponíveis no Brasil e por fornecedores situados no território nacional. Por fim, dentre os medicamentos de eficácia comprovada, deve privilegiar aqueles de menor custo, como os genéricos. (BARROSO, 2017, p. 37)

\subsubsection{A razoabilidade da pretensão}

No contexto dessas demandas, em que se venha a discutir a alteração das listas, é possível cogitar ainda de outros parâmetros complementares, capazes de orientar as decisões na matéria. Confiram-se. a) O Judiciário só pode determinar a inclusão, em lista, de medicamentos de eficácia comprovada, excluindo-se os experimentais e os alternativos; b) $\mathrm{O}$ Judiciário deverá optar por substâncias disponíveis no Brasil (Ministro Cezar Peluso, no RE 411.557/DF); c) O Judiciário deverá optar pelo medicamento genérico, de menor custo; d) O Judiciário deverá considerar se o medicamento é indispensável para a manutenção da vida.

Canela Júnior (2011) esclarece que os direitos fundamentais, que protegem os bens da vida, são efetivados pelo Poder Judiciário, e acrescenta:

Para corrigir as omissões das demais formas de expressão do poder estatal, o Poder Judiciário, entretanto, age de forma integradora, por meio da jurisdição, mas com amplos poderes coercitivos, necessários à concretização do provimento jurisdicional. [...] nas hipóteses de insatisfação, a jurisdição é o veículo natural para a concessão do remédio jurídico necessário para a pacificação social. O conflito existente entre os titulares do direito fundamental social e a conduta do Estado deve ser solucionado imperativamente pela jurisdição, mediante a "atuação da vontade concreta da lei”. (CANELA JÚNIOR, 2011, p. 92-93, grifo nosso)

\subsubsection{A disponibilidade financeira do Estado: a reserva do possível}

Questão ligada ao orçamento público e ao planejamento governamental. Orçamento não é absoluto, sendo suscetível a despesas inesperadas (quando não provisionadas previamente). Na Despesa Pública, a classificação por categorias econômicas prevê, dentro das despesas de capital, tipos de transferências de capital (diversas), dentre as quais as sentenças judiciárias. (VIGNOLI e FUNCIA, 2014, p. 41) 
De acordo com SANTOS e LOPES (2018), a doutrina majoritária entende que os limites impostos pela reserva do possível existem e não podem ser ignorados. A finalidade do Estado, ao arrecadar impostos para obras e políticas públicas, é a de concretizar os objetivos da Constituição, previstos em seu terceiro artigo. A Administração deve concretizar os elementos fundamentais da dignidade da pessoa humana (o mínimo existencial), preconizada na Constituição de 1988 e, secundariamente, avaliaria quais outros programas receberiam dotação orçamentária (SANTOS e LOPES, 2018, p. 40). Portanto, são dignos de receber a tutela jurisdicional do seu direito à saúde todo cidadão que se ver desamparado nesta área sensível.

\section{ALGUMAS INDAGAÇÕES: PROPOSTAS PARA REFFLEXÃO}

Diante dos diferentes posicionamentos doutrinários apresentados, vislumbram-se algumas propostas para reflexões e novos estudos, por outros autores, para além deste artigo:

- O que seria o mínimo existencial, especialmente para a saúde pública?

- Como conciliar necessidades ilimitadas com recursos limitados?

- Existe um vácuo representativo no Legislativo e no Executivo, ocupado pelo Judiciário, na definição do que seria uma pretensão razoável em termos de saúde pública?

- As decisões do Supremo Tribunal Federal podem acelerar a produção Legislativa?

- A criação dos Juizados Especiais Cíveis e a aplicação da Lei Geral de Greve aos servidores públicos (para suprir lacuna que o Legislativo deixou persistir por muitos anos) seriam políticas públicas que deram certo, com origem no Judiciário?

\section{CONCLUSÕES}

A intervenção do Judiciário na provisão do direito à saúde deve observar alguns requisitos: garantia do mínimo existencial, razoabilidade da pretensão e disponibilidade 
financeira do Estado. Ocorre que a crescente judicialização tem se mostrado incompatível com o equilíbrio do orçamento público, desorganizando o planejamento da Administração.

O planejamento da assistência via SUS e seus aspectos orçamentários precisam ser aperfeiçoados ou as Defensorias e o Ministério Público continuarão ajuizando ações individuais e coletivas, visto que, na inteligência do STF, a argumentação da reserva do possível não pode ser invocada pelo Poder Público com o propósito de inviabilizar a implementação de políticas públicas definidas na própria Constituição.

A conjuntura lança um desafio aos representantes dos três poderes, aos operadores do Direito, às associações e outros grupos de interesse, mas especialmente, aos que estão mais diretamente envolvidos na formulação de políticas públicas: identificar e mensurar (ou estimar com mais precisão) o que seria o mínimo existencial em cada área. Eis um desafio.

\section{REFERÊNCIAS}

BANDEIRA DE MELLO, Celso Antônio. Eficácia das normas constitucionais e direitos sociais. São Paulo: Ed. Malheiros, 2015.

BARCELLOS, Ana Paula de. A eficácia jurídica dos princípios constitucionais: o princípio da dignidade da pessoa humana. Rio de Janeiro: Renovar, 2002, p. 248-253.

BARROSO, Luís Roberto. Da falta de efetividade à judicialização excessiva: direito à saúde, fornecimento gratuito de medicamentos e parâmetros para a atuação judicial. UERJ, 2007. Disponível em < https://www.conjur.com.br/dl/estudobarroso.pdf $>$. Acesso em $14 \mathrm{dez}$. 2017.

Judicialização, ativismo judicial e legitimidade democrática. Revista (SYN)THESIS, UERJ [on-line]. Capa, vol. 5, n. 1, p. 23-32 (2012). Disponível em < https://www.e-publicacoes.uerj.br/index.php/synthesis/article/view/7433/5388>. Acesso em 17 jan. 2019.

BERCOVICI, Gilberto. Teoria do Estado e teoria da constituição na periferia do capitalismo: breves indagações críticas. In: NUNES, Antônio José Avelãs; COUTINHO, Jacinto Nelson de Miranda (orgs.). Diálogos Constitucionais: Brasil/Portugal. Rio de Janeiro: Renovar, 2004. 
BRASIL. Advocacia-Geral da União. Consultoria-Geral da União. Consultoria Jurídica da Advocacia Geral da União junto ao Ministério da Saúde - CONJUR/MS. Judicialização da saúde no Brasil: desafios para a mediação. Brasília, 2017. Disponível em < http://portalarquivos2.saude.gov.br/images/pdf/2017/maio/17/JUDICIALIZACAO\%20DA\%2 0SAUDE\%20NO\%20BRASIL\%20Desafios\%20para\%20a\%20mediacao.pdf>. Acesso em 27 jan. 2019.

Constituição Federal de 1988. Congresso Nacional, Brasília, 1988.

Ministério da Saúde. Secretaria de Ciência, Tecnologia e Insumos Estratégicos. Departamento de Assistência Farmacêutica e Insumos Estratégicos. Relação Nacional de Medicamentos Essenciais: RENAME 2017. Ministério da Saúde, Brasília: 2017. 210 p.

CANELA JUNIOR, O. A efetivação dos direitos fundamentais através do processo coletivo: um novo modelo de jurisdição. Inédito. Tese (Doutorado em Direito) - Faculdade de Direito. Universidade de São Paulo. São Paulo, 2009.

Controle judicial de políticas públicas. São Paulo: Saraiva, 2011.

FERNANDES, Márcio V. F. Judicialização de políticas públicas de saúde: impactos demonstrados no orçamento federal do SUS. 100 f. Dissertação (Mestrado em Direito) Programam de Pós-Graduação em Direito da Universidade Federal do Estado do Rio de Janeiro, Rio de Janeiro, 2019.

FERREIRA FILHO, Manoel Gonçalves. Direitos humanos fundamentais. São Paulo: Saraiva, 1996.

GOUVÊA, Marcos Maselli. O controle judicial das omissões administrativas. Rio de Janeiro. Forense, 2003.

GRINOVER, Ada Pellegrini. O controle de políticas públicas pelo poder judiciário. In: SALIBA, Aziz Tuffi; JÚNIOR GOMES, Luiz Manoel; ALMEIDA, Gregório Assagra. (Orgs.) Direitos Fundamentais e sua proteção nos planos interno e internacional. Belo Horizonte: Arraes Editores, 2010, p. 1-20. 
MEZZAROBA, Orides; MONTEIRO, Cláudia Servilha. Manual de metodologia da pesquisa no direito. 8. ed. São Paulo: Saraiva Educação, 2019.

MORAIS, José L. B. e BRUM, Guilherme V. Políticas públicas e jurisdição constitucional: entre direitos, deveres e desejos. Porto Alegre: Livraria do Advogado, 2016.

RIBAS, Giovanna Paola Primor e SOUZA FILHO, Carlos Frederico Marés de. Judicialização das políticas públicas e o Supremo Tribunal Federal. Revista de Direito PUC, n.44 p. 36 a 50 jan./jun. 2014. Disponível em < http://direitoestadosociedade.jur.pucrio.br/media/44artigo2.pdf>. Consulta em 10 fev. 2018.

SALIBA, Aziz Tuffi; JÚNIOR GOMES, Luiz Manoel; ALMEIDA, Gregório Assagra. Direitos fundamentais e sua proteção nos planos interno e internacional. Belo Horizonte: Arraes Editores, 2010.

SANTOS, Alethele de Oliveira; LOPES, Luciana Tolêdo (organizadoras). Coletânea direito à saúde: Dilemas do fenômeno da judicialização da saúde. Brasília (DF): CONASS (Conselho Nacional de Secretários de Saúde). 2018 - $1^{\text {a }}$ Edição. 319 p.

SECCHI, Leonardo. Análise de políticas públicas: diagnóstico de problemas, recomendações de soluções. São Paulo: Cengage Learning, 2016.

VIGNOLI, Francisco Humberto; FUNCIA, Francisco Rózsa. Planejamento e orçamento público. Rio de Janeiro: Editora FGV, 2014. 